\title{
Time Course of MERS-CoV Infection and Immunity in Dromedary Camels
}

\author{
Benjamin Meyer, Judit Juhasz, Rajib Barua, \\ Aungshuman Das Gupta, Fatima Hakimuddin, \\ Victor M. Corman, Marcel A. Müller, \\ Ulrich Wernery, Christian Drosten, Peter Nagy
}

Knowledge about immunity to Middle East respiratory syndrome coronavirus (MERS-CoV) in dromedary camels is essential for infection control and vaccination. A longitudinal study of 11 dam-calf pairs showed that calves lose maternal MERS-CoV antibodies 5-6 months postparturition and are left susceptible to infection, indicating a short window of opportunity for vaccination.

$\mathrm{I}^{\mathrm{n}}$ n 2012, Middle East respiratory syndrome coronavirus (MERS-CoV) emerged on the Arabian Peninsula (1). As of February 2016 the virus has caused 1,638 human infections, including 587 deaths (2). Zoonotic transmission of MERS-CoV was suspected early on (3). Dromedaries on the Arabian Peninsula and on the African continent have harbored MERS-CoV-specific antibodies for at least 20 30 years (3-7), long before the first human infections were recognized. Additionally, detection of MERS-CoV nucleotide sequences in throat swab specimens from camels confirmed the presence of the virus in these animals (8). The existence of an active animal reservoir receives additional support by epidemiologic investigations that found no sustained human-to-human transmission in MERS-CoV-affected countries such as Saudi Arabia (9).

As documented, primary infections in humans have occurred through contact with infected dromedaries, and measures to prevent primary human infections need to focus on the camel-human interface $(8,10)$. However, it has been unclear how MERS-CoV transmission is maintained in camels and which factors drive virus transmission from camels to humans. Clarifying the infection pattern of MERS-CoV in herds of dromedary camels is key to the design of herd management and vaccination strategies to control the source

Author affiliations: University of Bonn Medical Centre, Bonn, Germany (B. Meyer, V.M. Corman, M.A. Müller, C. Drosten); Deutsches Zentrum für Infektionsforschung, Braunschweig, Germany (V.M. Corman, C. Drosten); Emirates Industries for Camel Milk and Products, Dubai, United Arab Emirates (J. Juhasz, R. Barua, A. Das Gupta, P. Nagy); Central Veterinary Research Laboratory, Dubai (F. Hakimuddin, U. Wernery)

DOI: http://dx.doi.org/10.3201/eid2212.160382 of human infections. Preliminary information is limited to observations of lower seroprevalences in juvenile compared with adult camels and higher viral load upon MERS-CoV infection in juveniles $(4,5,11)$. Hence, infections in juvenile camels might drive transmission of MERS-CoV to humans.

\section{The Study}

We monitored MERS-CoV-specific antibody levels in 11 pairs of camel dams and their calves at monthly intervals over the course of 1 year postparturition. These animals were born and raised on a closed commercial camel dairy farm in the United Arab Emirates that had a strict animal health and biosecurity program. The total number of camels on the farm was $\approx 4,500$. Animals are kept in open paddocks and are grouped according to the age of their calves and production stage. Despite high standards of hygienic husbandry and biosecurity, the transmission of pathogens within the farm cannot be completely eliminated. Therefore, the entire farm is 1 epidemiologic unit. The 11 damcalf pairs investigated in this study were kept in different fenced compartments within 100-150 m from each other. However, all these animals were kept together with other dam-calf pairs in the same paddock throughout lactation. All camel calves were born during June 3-15, 2014.

Nasal swab specimens were taken from all 11 mothers and calves, and serum samples were obtained through jugular vein puncture. Blood cells were removed immediately after collection, and samples were stored at $-20^{\circ} \mathrm{C}$ until testing. Serum samples and nasal swabs were taken at the day of parturition, at 1 week and 1 month postparturition, and then at monthly intervals until June 2015. MERS-CoV RNA was detected through amplification of gene targets as described previously (12). Virus isolation was performed on Vero cells. MERS-CoV-specific IgG and neutralizing antibodies were determined by ELISA and microneutralization test as described previously $(5,10)$.

In general, maternal IgG antibodies in camels are not acquired via the transplacental route but through the intake of colostrum during the first 24 hours postparturition (13). After 24 hours, antibody levels in the dam's milk decrease rapidly, and IgG levels in calves' serum cease to rise (13). This pattern is reflected for MERS-CoV in this study. On the day of parturition, samples were collected from 5 of 11 dam-calf pairs studied. High levels of MERS-CoV-specific antibodies were observed in all dams, whereas no antibodies were detected in calves (Figure, panel A). At day 7 post- 

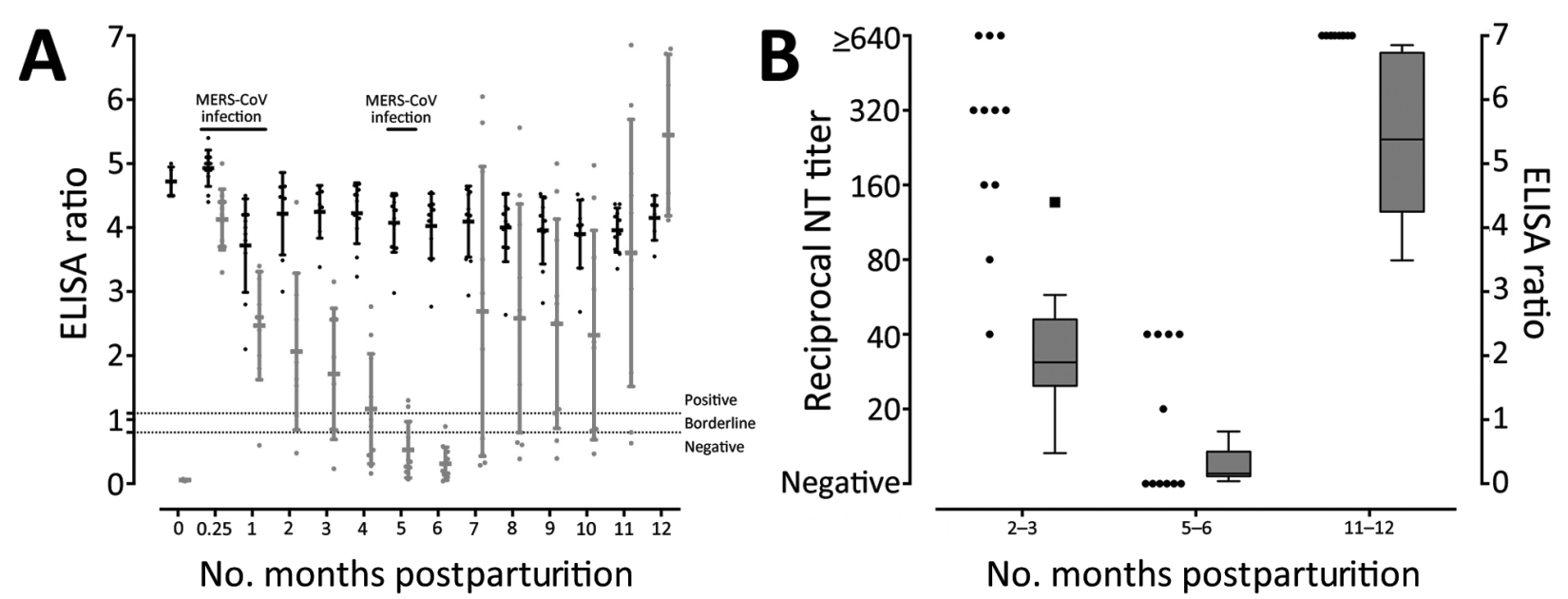

Figure. MERS-CoV-specific IgG antibody levels in dromedary camel dam-calf pairs, United Arab Emirates, 2014-2015. A) MERS-CoV spike protein S1-domain-based ELISA ratios of individual samples (dots) plus mean (horizontal line) and SD (error bars) over the course of 1 year for dams (black dots) and calves (gray dots). Ratios were calculated by dividing the ELISA optical density at $450 \mathrm{~nm}$ of each sample by that of a calibrator to minimize interassay variation. Dashed lines indicate cutoff values for positive (ratio 1.1) and borderline (ratio 0.8) samples. MERS-CoV infection indicates time points where MERS-CoV RNA was detected in camels. B) Neutralizing titers of individual samples from camel calves at selected time points determined by microneutralization test (dots). For comparison, ELISA ratios for the selected time points are shown in parallel as a boxplot diagram; box represents $50 \%$ of the complete dataset from the first to the third quartile, and whiskers are drawn according to the Tukey method. MERS-CoV, Middle East respiratory syndrome coronavirus; NT, neutralization test.

parturition, however, all 11 camel calves had high MERS$\mathrm{CoV}$-specific antibody levels. These levels declined during the first 6 months postparturition, whereas IgG in dams remained constantly at high levels. The neutralizing activity of IgG was confirmed by microneutralization tests on serum samples from calves collected 2-3 months, 5-6 months, and 1 year after birth (Figure, panel B). After 5-6 months, serum from 6 of 11 calves had completely lost their neutralizing activity. The remaining 5 calves had low neutralizing titers, ranging from 1:20 to 1:40 (Figure, panel B).

To examine possible correlations between antibodies and MERS-CoV infection, we examined shedding of MERS-CoV in nasal swab specimens. During the first 5 months postparturition, MERS-CoV RNA was detected sporadically on days 7 and 30 (Table). Infectious virus was isolated only from calves but not dams. At 6 months postparturition, when calves showed the lowest antibody titers, MERS-CoV RNA was detected in 2 of 11 calves (Table), indicating active MERS-CoV infection. All calves seroconverted during the following weeks (Figure, panel A); 1 calf had meanwhile been euthanized because of a congenital forelimb deformity. All calves showed high reciprocal neutralizing titers of $\geq 640$ at $11-12$ months postparturition.

\section{Conclusions}

This longitudinal study of natural MERS-CoV infections in camels confirms assumptions from preliminary crosssectional studies in camels $(4,5,11)$. MERS-CoV infection appears to predominantly affect young, immunologically naive animals. Serum antibodies might not have been sufficient to mediate protective immunity in the respiratory tract because dams and calves were sporadically infected even as maternal antibodies peaked at day 7 postparturition. These findings are consistent with earlier reports of MERS$\mathrm{CoV}$ reinfection in seropositive camels $(4,11)$. Nevertheless, our findings of virus isolation from calves but not dams are in line with earlier observations of reduced viral load in seropositive camels on reinfection $(11,14)$, indicating

\begin{tabular}{|c|c|c|}
\hline \multicolumn{3}{|c|}{$\begin{array}{l}\text { Table. MERS-CoV nucleic acid detection in nasal swab } \\
\text { specimens from camel dam-calf pairs, United Arab Emirates, } \\
\text { 2014-2015* }\end{array}$} \\
\hline \multirow{2}{*}{$\begin{array}{l}\text { Months } \\
\text { postparturition }\end{array}$} & \multicolumn{2}{|c|}{ No. positive/no. tested (\%) } \\
\hline & Adults† & Calves $\ddagger$ \\
\hline 0 & $0 / 5$ & $0 / 5$ \\
\hline 0.25 & $3 / 11(27.2)$ & $2 / 11(18.2) \S$ \\
\hline 1 & 2/11 (18.2) & $5 / 11(45.5)$ \\
\hline 2 & $0 / 11$ & $0 / 11$ \\
\hline 3 & $0 / 11$ & $0 / 11$ \\
\hline 4 & $0 / 5$ & $0 / 5$ \\
\hline 5 & $0 / 11$ & $0 / 11$ \\
\hline 6 & $0 / 11$ & 2/11 (18.2)田 \\
\hline 7 & $0 / 10$ & $0 / 10$ \\
\hline 8 & $0 / 10$ & $0 / 10$ \\
\hline 9 & $0 / 10$ & $0 / 10$ \\
\hline 10 & $0 / 10$ & $0 / 10$ \\
\hline 11 & $0 / 10$ & $0 / 10$ \\
\hline 12 & $0 / 10$ & $0 / 10$ \\
\hline \multicolumn{3}{|c|}{$\begin{array}{l}\text { *One dam-calf pair was excluded after month } 6 \text { because the calf wa } \\
\text { euthanized for an unrelated condition. MERS-CoV, Middle East resp } \\
\text { syndrome coronavirus. } \\
\text { †5 MERS-CoV-positive specimens from adult camels were from } 4 \\
\text { individual animals. } \\
\text { †9 MERS-CoV-positive specimens from camel calves were from } 6 \\
\text { individual animals. } \\
\text { §Virus was isolated from both infected calves. } \\
\text { TVirus was isolated from } 1 \text { infected calf. }\end{array}$} \\
\hline
\end{tabular}


that neutralizing antibodies might not provide sterile immunity but could still reduce the viral replication level. The predominance of infection in young animals is better explained by the absence of immunity than by other factors, such as social group density, because the number of newborn camels in our study was negligible compared with the overall size of the herd at the farm. Moreover, young camels were not kept in a contiguous group but in small compartments, where they had more contact with their mothers than with other young animals. Calves are likely to have been infected through fomites or through adult animals shedding low quantities of virus.

Our findings have important implications for the prevention of human infections through camel herd management and camel vaccination. Camel breeding, even if involving a small number of newborn animals, should be classified as a risk for human acquisition of MERS-CoV. The greatest risk should be assumed for the time after the fourth month of life until the first wave of natural infections, which should occur during the first year of life in camels raised in MERS-CoV-endemic regions. Measures for the prevention of infection, such as personal protective equipment, hand hygiene, and environmental sanitation, as applied on the farm in our study, should be sufficient for protection, given that no human MERS-CoV illnesses occurred among staff and only 2 of 300 workers with regular contact with camels had detectable MERS-CoV-specific IgG antibodies. Because persons with underlying disease and the elderly show the most severe outcomes of MERS$\mathrm{CoV}$ infection, these groups should generally avoid farms where camel calves are being raised.

Our results also suggest that studies dealing with application and efficacy of MERS-CoV vaccines should be modified. A first study involving immunologically naive animals showed a sharp decline in virus secretion after vaccination (14). However, future vaccination trials should also investigate the effect of preexisting maternal antibodies on vaccine efficacy (15).

\section{Acknowledgments}

We thank Monika Eschbach-Bludau, Tobias Bleicker, and Sebastian Brünink for their excellent technical assistance and help with the camel sera.

This work was in part financially supported by the Zoonoses Anticipation and Preparedness Initiative (ZAPI, grant agreement no. 115760) within the Innovative Medicines Initiative (IMI call 11-IMI-JU-11-2013-04) and by the Deutsche Forschungsgemeinschaft (DR772/7-2).

Dr. Meyer is a postdoctoral fellow at the Institute of Virology at the University of Bonn Medical Centre. His research interests include the epidemiology and ecology of MERS-CoV and other zoonotic coronaviruses.

\section{References}

1. Zaki AM, van Boheemen S, Bestebroer TM, Osterhaus AD, Fouchier RA. Isolation of a novel coronavirus from a man with pneumonia in Saudi Arabia. N Engl J Med. 2012;367:1814-20. http://dx.doi.org/10.1056/NEJMoa1211721

2. World Health Organization. Middle East respiratory syndrome coronavirus (MERS-CoV)—Saudi Arabia [cited 2016 Feb 25]. http://www.who.int/csr/don/2-february-2016-mers-saudi-arabia/en

3. Reusken CB, Haagmans BL, Müller MA, Gutierrez C, Godeke GJ, Meyer B, et al. Middle East respiratory syndrome coronavirus neutralising serum antibodies in dromedary camels: a comparative serological study. Lancet Infect Dis. 2013;13:859-66. http://dx.doi.org/10.1016/S1473-3099(13)70164-6

4. Alagaili AN, Briese T, Mishra N, Kapoor V, Sameroff SC, Burbelo PD, et al. Middle East respiratory syndrome coronavirus infection in dromedary camels in Saudi Arabia. MBio. 2014;5:e00884-14. http://dx.doi.org/10.1128/mBio.01002-14

5. Meyer B, Müller MA, Corman VM, Reusken CB, Ritz D, Godeke GJ, et al. Antibodies against MERS coronavirus in dromedary camels, United Arab Emirates, 2003 and 2013. Emerg Infect Dis. 2014;20:552-9. http://dx.doi.org/10.3201/eid2004.131746

6. Corman VM, Jores J, Meyer B, Younan M, Liljander A, Said MY, et al. Antibodies against MERS coronavirus in dromedary camels, Kenya, 1992-2013. Emerg Infect Dis. 2014;20:1319-22. http://dx.doi.org/10.3201/eid2008.140596

7. Müller MA, Corman VM, Jores J, Meyer B, Younan M, Liljander A, et al. MERS coronavirus neutralizing antibodies in camels, eastern Africa, 1983-1997. Emerg Infect Dis. 2014;20:2093-5. http://dx.doi.org/10.3201/eid2012.141026

8. Haagmans BL, Al Dhahiry SH, Reusken CB, Raj VS, Galiano M, Myers R, et al. Middle East respiratory syndrome coronavirus in dromedary camels: an outbreak investigation. Lancet Infect Dis. 2014;14:140-5. http://dx.doi.org/10.1016/S1473-3099(13)70690-X

9. Müller MA, Meyer B, Corman VM, Al-Masri M, Turkestani A, Ritz D, et al. Presence of Middle East respiratory syndrome coronavirus antibodies in Saudi Arabia: a nationwide, crosssectional, serological study. Lancet Infect Dis. 2015;15:559-64. http://dx.doi.org/10.1016/S1473-3099(15)70090-3

10. Memish ZA, Cotten M, Meyer B, Watson SJ, Alsahafi AJ, Al Rabeeah AA, et al. Human infection with MERS coronavirus after exposure to infected camels, Saudi Arabia, 2013. Emerg Infect Dis. 2014;20:1012-5. http://dx.doi.org/10.3201/eid2006.140402

11. Hemida MG, Chu DK, Poon LL, Perera RA, Alhammadi MA, $\mathrm{Ng} \mathrm{HY}$, et al. MERS coronavirus in dromedary camel herd, Saudi Arabia. Emerg Infect Dis. 2014;20:1231-4. http://dx.doi.org/10.3201/eid2007.140571

12. Corman VM, Müller MA, Costabel U, Timm J, Binger T, Meyer B, et al. Assays for laboratory confirmation of novel human coronavirus (hCoV-EMC) infections. Euro Surveill. 2012;17:20334.

13. Kamber R, Farah Z, Rusch P, Hassig M. Studies on the supply of immunoglobulin $\mathrm{G}$ to newborn camel calves (Camelus dromedarius). J Dairy Res. 2001;68:1-7. http://dx.doi.org/10.1017/ S0022029900004635

14. Haagmans BL, van den Brand JM, Raj VS, Volz A, Wohlsein P, Smits SL, et al. An orthopoxvirus-based vaccine reduces virus excretion after MERS-CoV infection in dromedary camels. Science. 2016;351:77-81. http://dx.doi.org/10.1126/science.aad1283

15. Niewiesk S. Maternal antibodies: clinical significance, mechanism of interference with immune responses, and possible vaccination strategies. Front Immunol. 2014;5:446. http://dx.doi.org/10.3389/ fimmu.2014.00446

Address for correspondence: Christian Drosten, Institute of Virology, University of Bonn, Sigmund Freud Str 25, Bonn 53127, Germany; email: drosten@virology-bonn.de 